\title{
Toward Detection of Harmful Algae Blooms by in situ Surface Plasmon Resonance Spectroscopy
}

\author{
Sébastien LAURENT, Florent COLAS, Muriel \\ HAMELIN, Marie-Pierre CRASSOUS, Elisabeth \\ ANTOINE, Michel LEHAITRE, Chantal COMPERE \\ ERT / Interfaces \& Capteurs \\ IFREMER \\ Technopôle Pointe du Diable 29280 Plouzané FRANCE \\ e-mail : sebastien.laurent@ifremer.fr
}

\begin{abstract}
Among marine algae species, Alexandrium minutum produces a phycotoxin called paralytic shellfish poisoning (PSP) that is introduced in the food chain through the ingestion of phytoplankton by shellfishs, and later by human consumers. Thus, in situ monitoring of $A$. minutum proliferation in coastal seawater is of great economical importance for marine resources exploitation. Here, we propose a rapid test for the detection of $A$. minutum by surface plasmon resonance spectroscopy. First, whole genomic DNA is extracted from the algae. Second, a 677 bp long portion of the 28S ribosomal DNA is amplified by PCR. Third, the PCR product is detected by surface plasmon resonance spectroscopy onto a DNA functionalized gold substrate.
\end{abstract}

Keywords - surface plasmon resonance; spectroscopy; in situ; algal detection; PCR

\section{INTRODUCTION}

Alexandrium minutum is a world-wide spread dinophyceae belonging to the harmful algae group ; this species causing "red-tides" during algal blooms produces phycotoxins named "paralytic shellfish poisoning" (PSP) under specific environmental conditions. Then, shellfishes ingest that phytoplankton and concentrate PSP in their glands. Human consumption of those infested shellfishes induces an acute intoxication, leading to several non specific neuronal and gastrointestinal symptoms [1]. Thus, as an important public health problem, public authorities need to control seawater in order to prevent human intoxications. Actually, as the mechanisms of induction for toxin production by $A$. minutum is unclear, a three step alert system has been established ; a regular numeration of $A$. minutum in seawater eventually followed by the AOAC reference mouse assay and finally a quantification of the PSP toxins.

Up to now, coastal laboratories monitor routinely $A$. minutum proliferation using a manual technique implying first a sampling of seawater, second a long time consuming decantation, and third a microscopic counting of phytoplankton in the sample. However, this technique suffers from several limitations including the delay of sample treatment -24 hours - and the need of very good skills in taxonomic identification of phytoplankton. Thus, in situ monitoring could avoid the need to return samples into the laboratory before analysis

In this context, development of marine in situ instrumentation associated with a rapid sensitive detection protocol is a promising emerging alternative for those routine assays [2, 3]. More, as A. minutum levels vary sharply temporally and spatially, in situ measurements would help to better forecast blooms apparition.

\section{PROPOSED APPROACH}

In this context, we have developed an assay based on DNA biosensors. As a transducer, we chose an optical method known as surface plasmon resonance (SPR) spectrometry [4] because of its marker free detection and thus limiting consumables for a future in situ autonomous sensor.

We adopted Krechtmann-Raether configuration for our SPR spectrometer as shown in Fig. 1 ; a polarized white light beam is reflected at the interface between a high refractive index glass (F2) prism and a $50 \mathrm{~nm}$ gold layer and then analyzed through a spectrometer coupled to a CCD camera.

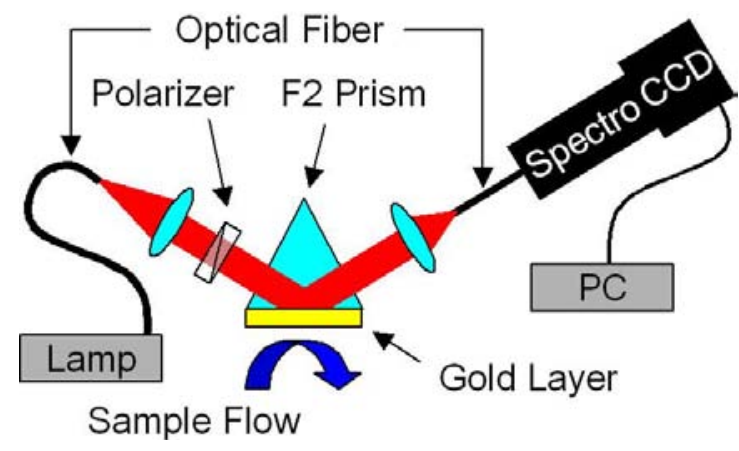

Figure 1. Schematic representation of our SPR spectrometer.

This work was supported by Brittany region through the PRIR BIRMA funding program. 
Briefly, the assay consisted first in a whole DNA extraction of $A$. minutum genome. In a second time, an single strand PCR was performed in order to amplify a specific sequence in the region coding for the $28 \mathrm{~S}$ ribosomal subunit of A. minutum. Finally, the single stranded PCR product was assayed over the DNA biosensor.

In this study, we demonstrate in a first part the feasibility of that approach using our home-made SPR spectrometer with synthetic short length complementary oligonucleotides. In a second part, we detected single stranded DNA PCR product of $A$. minutum.

\section{MATERIALS \& METHODS}

\section{A. SPR spectrotometer}

As imaged in Fig. 1, a white light beam produced by a tungsten-halogen lamp (HL-2000, Mikropack) was guided through a multimodal optical fiber (ThorLabs), collimated (ThorLabs) and $p$-polarized (ThorLabs). Light beam was then reflected on a $50 \mathrm{~nm}$ thick gold interface of a F2 glass disk (Schott) optically coupled with an equilateral F2 prism (ThorLabs). Reflected beam was finally focused and guided through a multimodal optical fiber for subsequent spectrum analysis via a Vis-NIR axial spectrometric system (Horiba Jobin-Yvon) coupled to a CCD camera (ST3200ME, SBIG). Frame rate was set at 0.5 image/s.

Signals were then processed by Visual Basic home-made software interface. The latter calculates the prediction of the plasmonic dip position employing the centroïd algorithm. Sensorgrams were finally analyzed and aligned with Origin software.

The microfluidic system was composed of 0.03 inch. ID Teflon tubing (Upchurch Scientific) for input / output and a $10 \mathrm{~mm}$ peek circular interaction chamber specially designed for F2 glass substrates. Waterproofness of the chamber was done by a O-ring joint (Cluzeau Info Labo). Liquid circulation was made by a peristaltic pump (Meredos) with a 1.02 mm ID Tygon tubing (Bioblock Scientific).

\section{B. Chemicals \& oligonucleotides}

All chemicals were purchased at Sigma-Aldrich. Thiolated, phosphorylated and non-modified oligonucleotides were purchased at Eurogentec, dissolved in sterile deionized water and conserved at $-20^{\circ} \mathrm{C}$ until use. Oligonucleotides figuring in Table 1 were all quantified spectrophotometrically before injection inside the microfluidic system.

\section{Whole DNA extraction from A. minutum culture}

A. minutum strain AM89BM (Bay of Morlaix, France) came from the IFREMER Centre de Brest collection. The inoculum was cultured in $\mathrm{f} / 2$ Guillard and Ryther medium [5] and grown axenically at $18 \pm 1^{\circ} \mathrm{C}$ under cool-white fluorescence light, at a photon flux of $150 \mathrm{mE} /\left(\mathrm{m}^{2} . \mathrm{s}\right)$ with 14:10 LD photoperiods.

Whole DNA extraction protocol followed CTAB methodology. $100 \mathrm{~mL}$ of culture was harvested and centrifuged 5 min at $6000 \mathrm{~g}$. The pellet containing cells was then mixed in 2X CTAB buffer (CTAB $2 \%$; Tris-HCl $100 \mathrm{mM}$; 2-mercaptoethanol 0,2\%; SDS $1 \%$; proteinase $\mathrm{K}$ $184 \mu \mathrm{g} . \mathrm{mL}^{-1}$ ) and incubated at $65^{\circ} \mathrm{C}$ for 90 minutes. Then, aqueous phase was purified after centrifugation (15 min, $12000 \mathrm{~g}$ ) in 3 steps using alternatively chloroform / isoamyl (24:1), phenol / chloroform / isoamyl (12:12:1), and chloroform / isoamyl (24:1) as extraction solvent mixes. DNA was precipitated from aqueous phase by adding frozen isopropanol $\left(-20^{\circ} \mathrm{C}\right)$ overnight and centrifugation (20 minutes, $10000 \mathrm{~g}, 4^{\circ} \mathrm{C}$ ). Pellet was purified with Wash Solution (ethanol $75 \%$; ammonium acetate $3 \mathrm{mM}$ ) and centrifuged (5 min, 10000 g). Finally, pellet was washed 2 times with ethanol (70\%) and dried. Extracted DNA was dissolved in sterile water and stored at $-20{ }^{\circ} \mathrm{C}$ until use.

\section{Obtention of ssDNA PCR product}

PCR primers were designed to amplify a specific sequence (677 bp) of $A$. minutum genome coding for ribosomal RNA of the 28S subunit. Primers sequences were the following ones : 5'TGCCAGCACTGATGTGTAAGGGCTT-3' (ARC) as forward primer and P-5'-ACCCGCTGAATTTAAGCATA3' (P-D1R) as 5' phosphorylated reverse primer.

$50 \mathrm{ng}$ of the previous extracted DNA was brought in a medium that contained : $\mathrm{MgCl}_{2} 1.5 \mathrm{mM}, 0.2 \mathrm{mM}$ of each dNTP, Taq polymerase $0.04 \mathrm{U} / \mu \mathrm{L}$ (Red Goldstart, Eurogentec), PCR buffer $1 \mathrm{X}$ (Eurogentec) and $0.5 \mu \mathrm{M}$ of each primer. PCR was carried out on a thermal cycler (Mastercycler, Eppendorf) with the following profile : $94{ }^{\circ} \mathrm{C}$ for $5 \mathrm{~min}$ (initial denaturation), followed by 40 cycles of $94^{\circ} \mathrm{C}$ for $1 \mathrm{~min}$ (denaturation), $50^{\circ} \mathrm{C}$ for $1 \mathrm{~min}$ (hybridization), $72{ }^{\circ} \mathrm{C}$ for $1 \mathrm{~min} 30 \mathrm{~s}$ (elongation), and $72{ }^{\circ} \mathrm{C}$ for $7 \mathrm{~min}$ (final elongation). PCR products were analyzed by agarose gel electrophoresis, purified with Qiaquick PCR purification kit (Qiagen) and quantified with a Nanodrop spectrophotometer (Thermo Scientific).

5' phosphorylated PCR strand was subsequently digested at $37^{\circ} \mathrm{C}$ during $15 \mathrm{~min}$ by lamba exonuclease $0.25 \mathrm{U} / \mu \mathrm{L}$ (Epicentre). Finally, ssDNA was purified with Qiaquick PCR purification kit and quantified with a Nanodrop spectrophotometer (Thermo Scientific).

\section{E. Injection protocol}

Before injection of biological molecules, air redemption from the microfluidic circuitry was achieved with an injection of ethanol. Whether for immobilization or target sequence detection, DNA strands were diluted in an hybridization buffer (50 mM HEPES; $0.5 \mathrm{M} \mathrm{NaCl}$ ) just before injection. For all experiments, reactions had taken place at room temperature $\left(22^{\circ} \mathrm{C}\right)$ and flow rate was set at $60 \mu \mathrm{L} / \mathrm{min}$. In order to minimize reactive consumption, the microfluidic circuitry was set in a closed configuration after $1000 \mathrm{~s}$ of injection for thiol immobilization and ssPCR product hybridization. Regeneration step was achieved with a $0.3 \mathrm{M} \mathrm{NaOH}$ aqueous solution. 


\section{RESUlts}

\section{A. Sensor sensitivity and accuracy}

Sensor sensitivity was measured following the injection of different sucrose concentrations ranging from $0.05 \%$ to $5 \%$ [6]. Setting two different incident angles, investigations were done for two ranges of wavelength excitation conditions (740 and $810 \mathrm{~nm}$ as baselines in water respectively). For each assay, recorded signals indicated a linear relationship between wavelength shifts vs. sucrose concentration (data not shown). As expected from theoretical calculations [7], near-IR shifting resulted in a $13 \%$ more sensitive signal.

In association with near-IR settings and differently from previous studies in the literature, signal normalization was here processed from the spectrum obtained with ethanol solution as its refractive index is sufficiently different from water one's to shift outside the detection window. That protocol offers the advantage to limit spectral distortions coming from differences of transmittance and reflectance between TM vs. TE polarizer modes ; as a result, normalized spectra offer a shape with higher symmetry for the dip (data not shown). Consequently, a $13.5 \%$ increase of sensitivity was observed through calibration curves.

Following those experimental conditions and signal process, sensor optical sensitivity $\delta \lambda \delta$ n was estimated to $6321 \mathrm{~nm} / \mathrm{RIU}$ considering $810 \mathrm{~nm}$ as dip baseline.

Adopting a home-made improved version of "centroïd" signal processing published by Chinowsky et al. [8], we were able to obtain a dip prediction below the spectrometer resolution $(0.15 \mathrm{~nm})$. Signal noise standard deviation of $7.5 .10^{-3} \mathrm{~nm}$ was measured. Thus, refractive index resolution was estimated at $3.56 \times 10^{-6} \mathrm{RIU}$.

\section{B. Sensor functionalization}

A synthetic 25-mer DNA 5'-thiolated sequence Amin25-SH - (Table 1) coding for the $28 \mathrm{~S}$ ribosomal subunit of $A$. minutum was immobilized onto a gold substrate via thiol chemisorption chemistry. After injection of $1 \mu \mathrm{M}$ Amin25-SH diluted in running buffer - HEPES $0.05 \mathrm{M} \mathrm{NaCl}$ $0.5 \mathrm{M}-$, a total wavelength shift $\Delta \lambda$ of $4.8 \mathrm{~nm}$ was observed. From equation (1), assuming that $\delta n / \delta C$ for nucleic acids (note $C$ as concentration in $\mathrm{pg} / \mathrm{mm}^{3}$ ) is $1.9 \times 10^{-10} \mathrm{~mm}^{3} / \mathrm{pg}$ [9] and that penetration depth of the plasmon wave $L_{Z C}$ is 110 $\mathrm{nm}$ for the range of wavelengths scanned, it is possible to determine a DNA probe density $\Gamma$ of $4.40 \mathrm{pg} / \mathrm{mm}^{2}$ at the sensor surface.

$$
\Gamma=\frac{\Delta \lambda \cdot L_{Z C}}{\left(\frac{\delta \lambda}{\delta n}\right) \cdot\left(\frac{\delta n}{\delta C}\right)}
$$

That calculated surface density of $56.30 \mathrm{fmol} / \mathrm{mm}^{2}$ $\left(3.39 \times 10^{10}\right.$ molecules $\left./ \mathrm{mm}^{2}\right)$ is in good agreement with other published results for a $0.5 \mathrm{M} \mathrm{NaCl}$ containing running buffer $[10,11]$.

\section{Models for ssDNA PCR hybridization}

Hybridization reaction was explored with synthetic oligonucleotide models. As described in Table 1, we chose DNA complementary sequences of different lengths - 25, 50 and 100 bases - and overlapping the 3 ' end of the final ssDNA PCR product from $A$. minutum.

TABLE I. DNA SEQUENCES

\begin{tabular}{|c|c|}
\hline $\begin{array}{l}\text { Sequence } \\
\text { Name }\end{array}$ & Sequence description \\
\hline Amin25-SH & 5'-AAGCCCTTACACATCAGTGCTGGCA-3' \\
\hline Amin25c & 5'-TGCCAGCACTGATGTGTAAGGGCTT-3' \\
\hline Amin50c & $\begin{array}{l}\text { 5’-CAAGACGGGTCAAGCAGAAACATTTTGCC } \\
\text { AGCACTGATGTGTAAGGGCTT-3' }\end{array}$ \\
\hline Amin100c & $\begin{array}{l}\text { 5'-GTTTGCCACCCACGAACTTGCACATCTGTT } \\
\text { AGACTCCTTGGTCCGTGTTTCAAGACGGGTC } \\
\text { AAGCAGAAACATTTTGCCAGCACTGATGTG } \\
\text { TAAGGGCTT-3' }\end{array}$ \\
\hline $\begin{array}{l}\text { Negative } \\
\text { control }\end{array}$ & 5‘-CCTTGGTCCGTGTTTCAAGA-3’’ \\
\hline
\end{tabular}

DNA hybridization kinetics were observed for those three sequences as shown in Fig. 2. Else, $1 \mu \mathrm{M}$ of non reactive DNA strand was also injected as negative control (Table 1). As expected, hybridization kinetics follow a first order Langmuir model. For all DNA complementary strands, no difference was observed during dissociation kinetic $\left(k_{D}\right)$. Variation of kinetic behaviour was thus attributed to association phase $\left(k_{A}\right)$. In fact, the longest the DNA sequence was, the lowest the $k_{A}$ appears. That observation is in phase with a random approach of the target oligonucleotide to the probe; the probability of good matching decreases while DNA length increases.

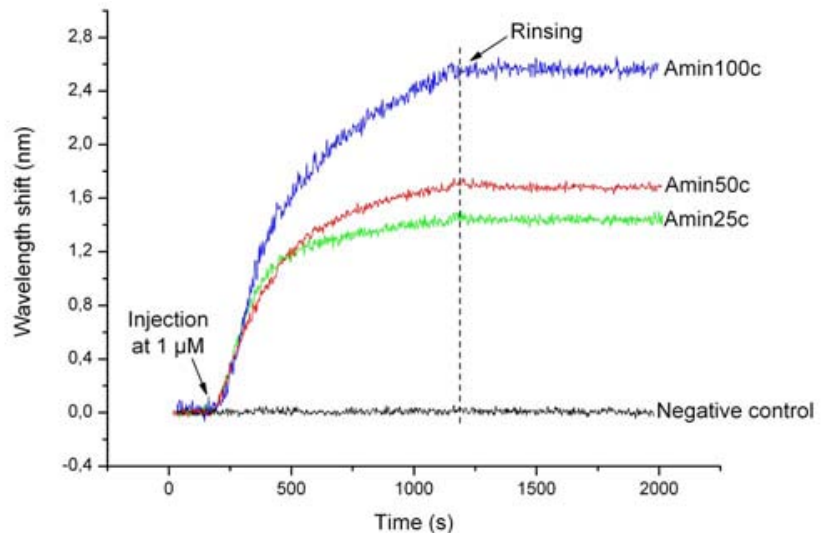

Figure 2. Hybridization kinetic signals for different lenghts of DNA targets ; injections were carried at a concentration of $1 \mu \mathrm{M}$ diluted in running buffer.

More, considering that molecular weight stills proportional vs. surface plasmon resonance wavelength shift, steady-state hybridization signals indicated a capture efficiency of $31.2 \%, 21.8 \%$ and $11.9 \%$ for Amin25c, Amin50c and Amin100c respectively. That observation suggests a steric hindrance of the hybridization reaction over the sensor 
surface. As PCR product is a 677 bases long DNA, further optimization of immobilization chemistry will be necessary to better control probe density in order to increase target DNA capture.

Afterwards, an estimation of the biological sensor sensitivity was assayed for Amin100c. In this way, Fig. 3 represents aligned hybridization kinetic signals obtained after injection of Amin100c at different concentrations ranging from $1 \mu \mathrm{M}$ down to $10 \mathrm{nM}$. No dissociation was observed during the rinsing phase.

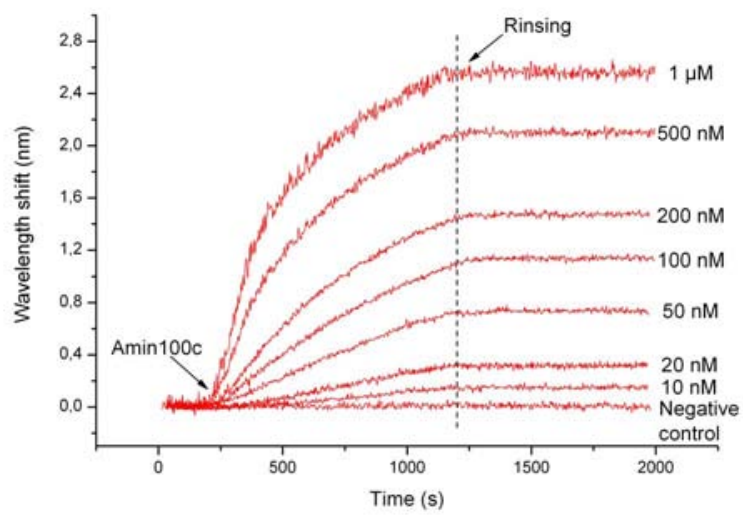

Figure 3. Hybridization kinetic signals for Amin100c at different concentrations ranging from $1 \mu \mathrm{M}$ to $10 \mathrm{nM}$ diluted in running buffer.

From Fig. 4, signal variation adopts an exponential shape with a plateau corresponding to saturation concentrations. More, from their linear part, those results indicate an estimated limit over detection (LOD) in the range of $4.5 \mathrm{nM}$, that is in the same order of magnitude than other SPR based systems [12] and is compatible with PCR assays. Like above mentioned, a negative control assay was performed indicating no signal during the injection.

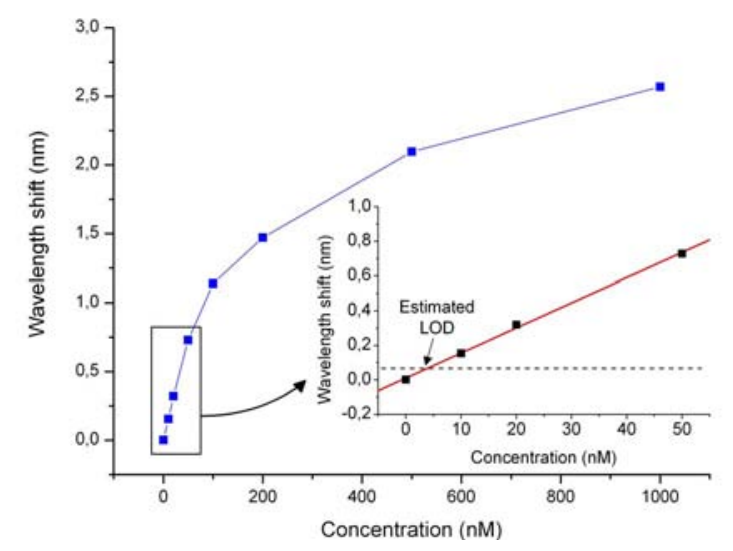

Figure 4. Sensor sensitivity for Amin100c hybridization ; insert indicates an estimated LOD based on $3 \sigma$ noise signal $\left(2.25 .10^{-2} \mathrm{~nm}\right)$.

Sensor reproducibility was examined too ; biosensor showed the same signal amplitude even after more than 30 cycles (data not shown). Such a lifetime would be compatible with an autonomous in situ monitoring application.

\section{PCR based assay for A. minutum}

From previous results, we expected to $\operatorname{detect} A$. minutum genome via a PCR based assay. For that, a culture of $A$. minutum (AM89BM) was harvested and lysed following a CTAB DNA extraction protocol. Then, a D1-D2 specific sequence coding for $28 \mathrm{~S}$ ribosomal subunit of $A$. minutum genome was amplified by PCR. Then, dsPCR product was digested by $\lambda$-exonuclease. Finally, ssDNA was eluted in water using Qiaquick (Qiagen) and quantified spectrophotometrically. Afterwards, PCR product was diluted in running buffer just before injection.

Fig. 5 exhibits an overlay of hybridization kinetics obtained for a range from $50 \mathrm{nM}$ down to $6.25 \mathrm{nM}$ of PCR product injected on the DNA sensor during $10000 \mathrm{~s}$. Here, a $1.35 \mathrm{~nm}$ saturation signal was attained with $50 \mathrm{nM}$ of PCR product ; thus, an estimation of hybridization efficiency is $1.1 \%$ that is lower than for its 100 bases analog. Wavelength shifts behave quasi-linearly vs. time, but rather slower than as shown in Fig. 3 for Amin100c. Such a limited and slow response can be explained by steric hindrance over the biosensor surface and by the possible folding of ssDNA products. Further experiments about injection protocol will attribute the origin of those limitations.

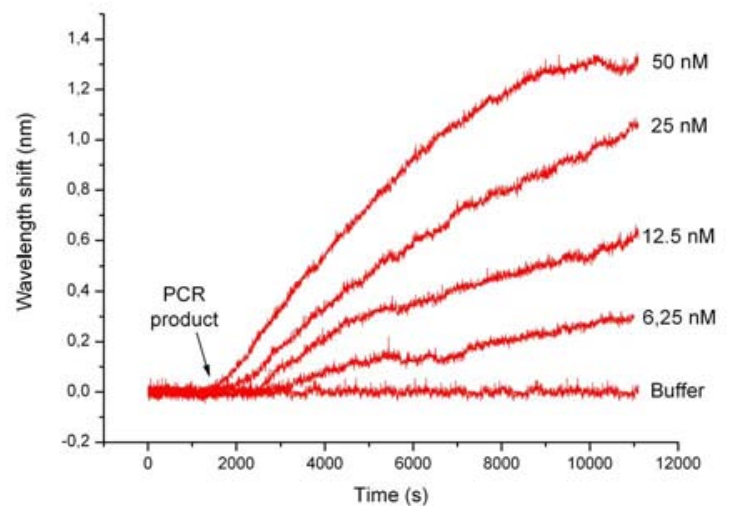

Figure 5. Hybridization signal recorded during a typical PCR assay followed by a sensor regeneration phase $(0.3 \mathrm{M} \mathrm{NaOH})$.

As indicated in Fig. 6, considering PCR product concentrations below $12.5 \mathrm{nM}$, a linearity is observed. By linear regression, an estimated LOD of $1.6 \mathrm{nM}$ was determined that is consistent with Zezza et al. work [13].

Finally, specificity of the biosensor was assayed ; for that purpose, a sequence coding the $18 \mathrm{~S}$ ribosomal subunit of $A$. minutum was amplified by asymmetric PCR and purified as described above. After injection, no significant signal was observed, proving thus the good specificity of the analytical technique (data not shown).

Several PCR assay were tried with the same sensor surface using $\mathrm{NaOH} \mathrm{0.3} \mathrm{M}$ as regeneration cocktail, proving that our system would be able to get reused for many analysis (data not shown). 


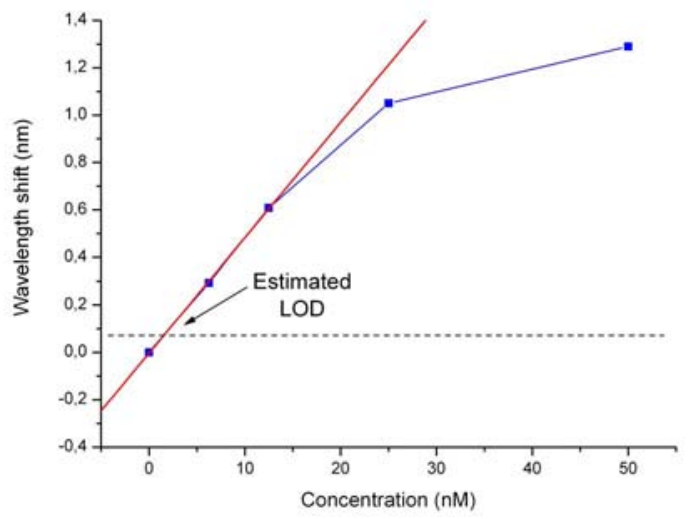

Figure 6. Sensor sensitivity for PCR product hybridization ; insert indicates an estimated LOD based on $3 \sigma$ noise signal $\left(2.25 .10^{-2} \mathrm{~nm}\right)$.

\section{CONCLUSIONS}

This study has demonstrated that improved signal treatment for SPR sensing - i.e. upgraded centroïd algorithm and ethanol spectrum normalization - , leads to a costless powerful SPR spectrometer with a resolution of $3.56 \times 10^{-6}$ RIU.

In a first part, specific genome detection of $A$. minutum was assayed through targets of various lengths ; our results showed a decrease in sensor efficiency for longer synthetic oligonucleotides but stilled sensitive enough to detect less than $10 \mathrm{nM}$ of 100 bases DNA. In a second part, as far as we know and for the first time, PCR detection was assayed with a SPR spectrometer. Results indicated here a possible quantification of the PCR product below $12.5 \mathrm{nM}$; this constitutes the first step before a future quantification of $A$. minutum concentration in seawater.

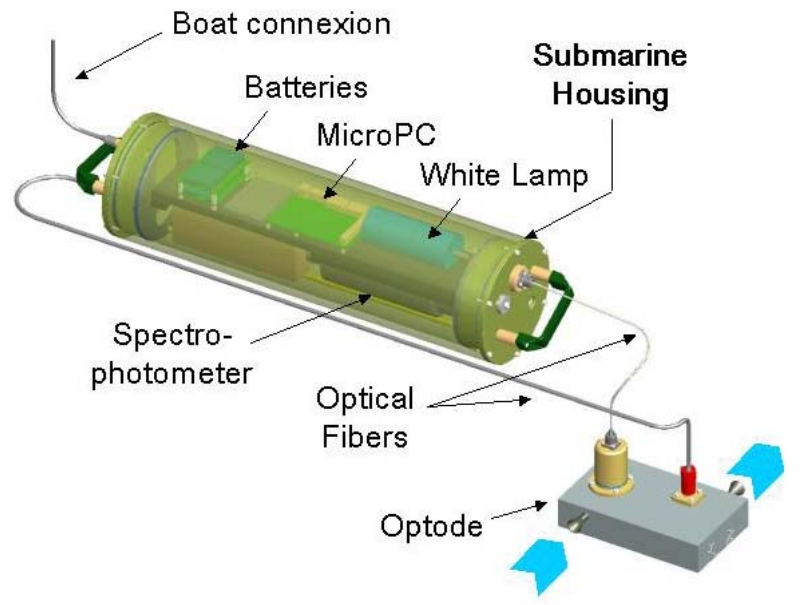

Figure 7. Schematic representation of our marine SPR spectrometer.
Finally, a marine conception of the instrument was designed for in situ detection of algal species. In that way, we have already built a submarine home-made SPR spectrometer (Fig. 7) for the need of future investigations.

\section{ACKNOWLEDGMENT}

We thank the region of Brittany for funding support to the PRIR-BIRMA program.

\section{REFERENCES}

[1] M. Campas, B. Prieto-Simon, and J. L. Marty, "Biosensors to detect marine toxins: Assessing seafood safety,” Talanta, vol. 72, no. 3, pp. 884-895, May, 2007.

[2] S. Diercks, K. Metfies, and L. K. Medlin, "Development and adaptation of a multiprobe biosensor for the use in a semi-automated device for the detection of toxic algae,” Biosensors \& Bioelectronics, vol. 23, no. 10, pp. 1527-1533, 2008.

[3] E. Turrell, E. Bresnan, C. Collins et al., "Detection of Pseudonitzschia (Bacillariophyceae) species and amnesic shellfish toxins in Scottish coastal waters using oligonucleotide probes and the Jellet Rapid Test (TM),” Harmful Algae, vol. 7, no. 4, pp. 443-458, 2008.

[4] M. Piliarik, and J. Homola, "SPR Sensor Instrumentation,” in Surface Plasmon Resonance Based Sensors, vol. 4, O.S. Wolfbeis, Eds. Springer Ser Chem Sens Biosens, 2006, pp. 95-116.

[5] R. R. L. Guillard, "Culture of phytoplankton for feeding marine invertebrates," Culture of Marine Invertebrate Animals, W. L. Smith, Chanley, M.H., ed., pp. 26-60, New York, USA: Plenum Press, 1975.

[6] D.R. Lide, Handbook of Chemistry and Physics $88^{\text {th }}$ CRC Press. Boca Raton, FL, 2007-2008.

[7] K. Johansen, H. Arwin, I. Lundstrom et al., "Imaging surface plasmon resonance sensor based on multiple wavelengths: Sensitivity considerations," Review of Scientific Instruments, vol. 71, no. 9, pp. 3530-3538, Sep, 2000.

[8] T. M. Chinowsky, L. S. Jung, and S. S. Yee, “Optimal linear data analysis for surface plasmon resonance biosensors,” Sensors and Actuators B-Chemical, vol. 54, no. 1-2, pp. 89-97, Jan, 1999.

[9] E. Bouffartigues, H. Leh, M. Anger-Leroy et al., "Rapid coupling of Surface Plasmon Resonance (SPR and SPRi) and ProteinChip based mass spectrometry for the identification of proteins in nucleoprotein interactions,” Nucleic Acids Res, vol. 35, no. 6, pp. e39, 2007.

[10] S. Peeters, T. Stakenborg, G. Reekmans et al., "Impact of spacers on the hybridization efficiency of mixed self-assembled DNA/alkanethiol films,” Biosens Bioelectron, vol. 24, no. 1, pp. 72-7, 2008.

[11] A. W. Peterson, R. J. Heaton, and R. M. Georgiadis, "The effect of surface probe density on DNA hybridization," Nucleic Acids Research, vol. 29, no. 24, pp. 5163-5168, 2001.

[12] X. D. Su, Y. J. Wu, and W. Knoll, "Comparison of surface plasmon resonance spectroscopy and quartz crystal microbalance techniques for studying DNA assembly and hybridization,” Biosensors \& Bioelectronics, vol. 21, no. 5, pp. 719-726, Nov, 2005.

[13] F. Zezza, M. Pascale, G. Mule et al., "Detection of Fusarium culmorum in wheat by a surface plasmon resonance-based DNA sensor,” Journal of Microbiological Methods, vol. 66, no. 3, pp. 529537, 2006. 